\title{
The Function and Field of Speech and Language in Neoliberal Education
}

\begin{abstract}
This paper explores the role of psychoanalysis in contemporary neoliberal management of higher education, as a critical resource and as an aspect of the problem it describes. The marketisation, privatisation and financialisation of the university sector is the context for a brief case example in which we see the logic of fantasy staged in a particular organisation, and this case example is followed by a review of the distinctive forms of management of subjectivity in higher education which sustain the context for such events. I bring aspects of Lacanian psychoanalysis to bear on the development of current neoliberal management strategies in universities, and then methodological principles are extracted from Lacan's 1953 foundational text 'The Function and Field of Speech and Language in Psychoanalysis'; the principles concern the application of psychoanalysis, the place of speech as site of truth, language conceptualised here as psychoanalytic discourse, the gap between speech and language manifested in alienation and symptoms, resistance expressed in jokes, and the formation of specific domains in which psychoanalytic reasoning is operative today. I argue that neoliberal management realises the worst aspects of the problems Lacan identifies in his text; knowledge as grounding for education and interpretation, treatment underpinned by charitable concern, and the performance of expertise tied to power. I focus on Lacan's warnings about the popularisation of psychoanalytic discourse, and conclude with comments on the way 'analysis' now takes place outside the clinic.
\end{abstract}

\section{Keywords}

Neoliberalism, higher education, Lacan, psychoanalysis, discourse

\section{Introduction}


Universities today are being transformed (McGettigan, 2013). State funding of public 'higher education' is being replaced by financialisation of the sector and by massive increases in tuition fees which will then reward popular courses and see disciplines that are deemed superfluous to immediate economic benefit and career success of the student go to the wall. The student is increasingly positioned as a 'customer' who will choose between different providers. Their own assessment of the value of their course is being assiduously harvested and represented by each university and each course pitted against the others. This shift in identity and aspiration of those who learn how to consume knowledge is being facilitated by the marketisation of the field of higher education and an internal privatisation of the state sector so that its different component parts will compete on what is viewed as a level playing field with the private sector (Lorenz, 2012).

This marketisation, privatisation and financialisation of the university sector is part of a neoliberal agenda by the capitalist state in which deregulation of education and welfare is carried out in the name of economic efficiency and individual responsibility (Harvey, 2007). The globalisation of management practices in higher education is here tied to neoliberal models of 'development' (Went, 2000, Zajda, 2005). The implementation of this agenda in higher education actually requires more intense managerial control rather than less, just as neoliberalism in general, which pretends to lift the burden of state restrictions on the free market, actually requires a strong state to deal with dissent or collective protest (Klein, 2008). This means that the organisation of work, of education and research as intellectual labour, is also undergoing a process of transformation, one which reconfigures the place of the scholar as well as the student.

Alongside the surveillance and control necessary to enable these political-economic institutional changes, and as condition for them to function, there is a degree of self-management and subjective satisfaction in the process that must be induced. It is that self-regulation of intellectual life as a site of emotional labour that I want to focus on in this paper as part of the 'emotional literacy' which informs research in universities (Burman, 2009). The shadow-side of the neoliberal restructuring of higher education is the formation of fantasy in the institutions, and our question is how psychoanalysis can be articulated with those changes as part of a more general 'psychologisation' of culture (De Vos, 2012). More precisely, how is psychoanalysis already 
articulated with those changes as a symbolic resource, how does it enter into the forms of resistance that are staged in universities as work organisations, and how might we develop psychoanalytic research that is critical of that process? My starting assumption is that the psychoanalyst Jacques Lacan had something useful to say about organizations (Contu et al., 2010), and so should now be put to work on universities as sites of emotional labour. I will develop an analysis which begins with a case example configured as an autoethnographic narrative (Ellis and Bochner, 2000), and which will then mobilise a specific conceptual frame drawn from one of Lacan's texts.

Lacan provides a complex and contradictory array of resources for cultural and institutional critique of organizations (e.g., Stavrakakis, 2008), some of which pertain directly to the role of 'discourse' structuring social relations outside the clinic (Clemens and Grigg, 2006, Lacan, 2007). However, it is the focus on speech and language in one of his key interventions into the field of psychoanalysis as such that offers us concepts for grasping not only how psychoanalysis might be 'applied' outside the clinic (e.g., Kenny and Fotaki, 2014) but also for prompting reflection on how psychoanalytic discourse structures subjectivity in educational institutions today.

'The function and field of speech and language in psychoanalysis' was a text that Lacan revised and reframed for publication in the Écrits (Lacan, 2006). In his review of the development of psychoanalysis in 1953 which was also a critique, Lacan drew attention to the language of psychoanalysis itself, and to what it meant to speak within it, to speak in and against that language. Here there is the rationale for a particular kind of clinical practice and the elaboration of a theoretical research programme which is also designed to function critically and reflexively. That is, it cuts against the organisations that claim to speak for psychoanalysis but which bury the question of truth in a series of bureaucratic procedures. Lacan's paper is particularly useful not only because it elaborates a distinctive turn in psychoanalysis toward language, but also because his critique of mainstream psychoanalytic institutions was of them as forms of organization. Lacanian psychoanalysis was henceforth to be characterized by a conceptual reworking of Freudian concepts and a political reading of the constant danger of recuperation of those concepts by the organizations that claim to speak for psychoanalysis (Parker, 2011). 
The bureaucratic procedures Lacan railed against accomplish two things: On the one hand, they gear the practice of psychoanalysis to conceptions of biology, behaviour and amelioration that underpin other rival forms of knowledge (psychiatry, psychology, psychotherapy); On the other hand, they inscribe Freudian ideas within the tracks of popular discourse to make it acceptable (Parker, 2011). The 1953 text was prepared as a statement which defended his practice as a psychoanalyst at a time when he was being excluded by the International Psychoanalytical Association - a process which concluded ten years later when Lacan founded his own training organisation - and so it marks, as a kind of manifesto, a new way of conceptualising psychoanalysis as a clinical and even political practice. Lacan's question in the preface to this text is suitably ambiguous, double-edged:

As a method based on truth and demystification of subjective camouflage, does psychoanalysis display an incommensurate ambition to apply its principles to its own corporation - that is, to psychoanalysts' conception of their role in relation to the patient, their place in intellectual society, their relations with their peers, and their educational mission? (Lacan, 1953: 200)

This question already raises a question for us about our own perhaps 'incommensurate ambition' to 'apply' the principles of psychoanalysis to organisations. We need to take seriously the incommensurability of psychoanalysis as such to this task on the one hand and the application of psychoanalysis to it on the other. This question of application today pertains not only to psychoanalysis' own 'corporation' but also to a variety of different work organisations that host and depend upon psychoanalytic discourse to structure the subjectivity of individuals within them. I argue that popularised forms of psychoanalytic discourse now fuel the distinctive forms of alienation that characterise the neoliberal governance of higher education institutions, and that Lacan's 1953 text can help us to address that. One way of doing that is to take seriously to the specific problems Lacan describes and so attend to the way that a kind of psychoanalytic logic is embedded in organisations today in times of neoliberalism. 
Our psychoanalytic sensitivity to speech and language in culture and in the institutions that formalise and reproduce that culture can then enable us to clarify and take a distance from that logic. Here we will take the case of 'higher education', our own corporation in which we are required to adhere to a specific form of educational mission, one which is often spelt out for us in the university 'mission statement', but which is implemented through corrective procedures that entail a measure of emotional control and violence. I will illustrate this by describing a case example in which we can see enacted the staging of a fantasy, the fantasy of revenge by an individual subject which is conditioned by contemporary institutional context. I then explore in more detail that institutional context of neoliberal educational management before turning to six principles from Lacan's text. These principles will give us the coordinates through which to approach the forms of subjection and fantasy of resistance, and it enables us to reflect on the assumption that psychoanalysis is appropriate to interpret what is happening now. I draw attention in the course of this description and analysis to how psychoanalytic discourse itself is an intimate part of that institutional context.

\section{The staging of fantasy}

The brief case example I am going to describe is one in which I am, from the beginning, implicated, and here I focus on my position as researcher in this context and in relation to this particular account (Ellis and Bochner, 2000). This account is formulated in relation to me in a particular position, which includes some kind of attribution of knowledge to me as psychoanalyst. In that respect I think it would be fair to say that the conversation in which this account appears constitutes 'a domain whose limits define the relativity of its operations' (Lacan, 1953: 214), and this domain is to some extent psychoanalytically informed. We see here staged a fantasy in which satisfaction, recognition, injury and revenge are symptomatically mobilised, a logic of fantasy that is culturally-institutionally constructed.

We can bring some order to these events by attending, following Lacan, to their temporal logic. This is not that of linear segmented 'clock time' but is a temporal logic which, Lacan (ibid.: 255) claims, confirms his remarks on the definition he gave as to the confines of the psychoanalytic 
clinic, and which includes 'a subject's time for understanding' which 'includes a psychological factor that escapes us by its very nature'. Lacan (ibid.: 237) spells out this 'logic' like this: ' $\ldots$ it is the certainty anticipated by the subject in the 'time for understanding' which - through the haste that precipitates the 'moment of concluding' - determines the other's decision that makes the subject's own movement an error or truth.'

The account I will describe can be understood - and I use that term 'understood' deliberately, so as not to pretend that there is no imaginary element here in the way I am framing this - as taking place in the third moment of an organisational crisis. I questioned management practices in my university concerning workload and appointment procedures which led to my suspension from the organisation, first moment. There followed a protracted campaign over several months by the union, students and colleagues in other universities, second moment. This was followed by a disciplinary hearing, lifting of the suspension, my refusal to return to work in the same department and resignation from the university, which I condense here as the third moment, the 'moment of concluding'. In this third moment of my narrative of discipline and resignation I will describe a conversation I had with a colleague that is also structured according to three moments which I describe here in this account as my colleague's staging of a fantasy of resistance. It is here that we find some suffering and resistance in the form of a joke.

It has long been noted in the organisational management literature that jokes made by those in power serve to emphasise and reinforce their position (e.g., Duncan, 1982), and that jokes can also function as forms of subversion and resistance (e.g., Hodgson, 2005). First, jokes of power. A few months before I was suspended I was called for my annual Professional Development Review (PDR), very unusually with two managers, the head of department and the dean of faculty, so I guessed it would be no laughing matter. My partner had been subjected to three and half hours of attack a few weeks before in her PDR, including being told she published too much, so I had an idea what to expect. Since the dean of faculty had not attended my reviews up to then, at the beginning I handed him a list of my publications. As he glanced through he said 'And I thought [your partner's] was bad'. I asked him what he meant, and the head of department interrupted and kept repeating that the dean was joking. The meeting became more acrimonious from that point on. I complained about this, and 
after my suspension and resignation the university decided to carry on with that particular investigation. The letter telling me that all had been in good order and I had no grounds for complaint included an observation on the dean's comment during the PDR that 'The remarks he made regarding your partner's publication list were made in good humour to lighten the conversation'.

In the third moment of the process of my narrative of discipline and resignation we come to an attempt at a joke against power. In that third moment I met a colleague from my department who asked if could discuss what was happening in the department and we had a long conversation over several hours in which something like a 'time for understanding' was created between us, a conversation that reminds me of Lacan's (ibid.: 247) remark that 'the speech value of a language is gauged by the intersubjectivity of the "we" it takes on". That is, embedded in the third moment which resolved the narrative of my suspension we together enacted the three moments of logical time Lacan describes (or, at least, the encounter can be grasped within the frame of that logic). I met with this colleague because although I was keen to disconnect myself from the institution I was intrigued that he wanted to talk, and wanted to know what he would say. This conversation staged a fantasy. The colleague knew that as well as being an academic I also work as a psychoanalyst. We speculated together about the background to the events, and the role of the new head of department and the dean of faculty.

The head of department was an ambitious obedient bureaucrat, a woman willing to act as middle-manager implementing executive decisions who would do this not simply by issuing a command that this or that task be carried out but by publically addressing their 'disappointment' to those who did not comply. The dean of faculty was a man simultaneously feminised by the process of bowing to demands of managers above him and masculinised, forced to assert his authority over subordinates.

At one late point in our conversation we recalled how when the dean had arrived in the university a few years before, other key figures in the faculty who had earlier supervised his $\mathrm{PhD}$ greeted the appointment with triumphant claims that he would do their bidding (and the phrase used at the time was that he would be 'under their thumb'). He quickly acted to sack both his PhD supervisor and another member of the supervision team. I commented that this was an 'Oedipal' struggle, and 
my colleague, a psychologist, asked me what I meant. I take this to be the first moment in the temporal logic of his staging of a fantasy. Note that psychology in the English-speaking world excludes and tries to forget what it views as Freudian non-science (Richards, 1989). My colleague then asked me directly whether I had deliberately provoked management. I said that I did not know that the response would be so sharp and fast, but that because I believed in the unconscious I supposed that there was something in me that must have known what was going to happen. I take this to be the second moment in this staging of a fantasy, a 'time for understanding'.

Now we come to the third moment of our conversation, the 'moment of concluding'. My colleague had already told me at length how the head of department patronised him and how angry it made him feel. He told me he felt that the only strategy he could adopt was to do exactly what he was told, but in the spirit of what called 'dumb insolence' which would convey to others (and covertly to her as well) that he did not really believe what he was doing and this would maintain his own dignity. He wanted to conform in such a way as to force the manager to reveal what a brow beater he considered her to be. He then said, and here we come to the moment where a fantasy is formulated, 'I want her to head-butt me in the face in public'.

This is where the 'hidden injuries' of the neoliberal university are for a moment made public, where one of the subjects of the university speaks of their experience and how they want to make the injuries visible and expose the agent of their misery. It was a joke, but a serious joke which displayed and perpetuated the position of the subject. We do not need to delve into the 'psychical development' of this subject, to pretend to understand what he meant in some kind of 'existential phenomenology' or to bring the 'analyst's being' to play in an interpretation of this fantasy. These three notions of 'psychical development', of 'existential phenomenology' and of the 'analyst's being' are, as we shall see, treated as problematic by Lacan and as speaking of the popularisation of psychoanalysis rather than of the truth of the subject. Instead we see here some matrix of fantasy in an organisation, but the kind of analysis we need is one which locates the fantasy in the context of prevailing discourses of power and subjectivity. These discourses are not unlocked by psychoanalysis, rather, they include it, and that is precisely why we are able to read them. 


\section{The shape of the problem}

In this paper I am concerned with the way the discourse of psychoanalysis in its broadest most inclusive popularised form informs not only institutional procedures but also the subjective responses through which lecturers and researchers cope with neoliberal demands on them and attempt to resist those demands. In order to appreciate how the peculiar intersubjective violence and emotional destructiveness of neoliberal management of education is now informed by psychoanalytic discourse we first need to grasp the nature of neoliberalism in relation to practices of administration in organisations developed to the mastery and transmission of knowledge.

Neoliberalism returns to what looks classical liberal political economy of the nineteenth century but with a twist (Harvey, 2007). The twist is that in place of the ostensibly rationalist contractual relations between workers and capitalist we now have an individual subject saturated with affect so that their own investment in the workplace becomes a target of and resource for management. Crucial to this saturation of the individual subjects with affect is the role of psychoanalysis, which does not merely provide a commentary on the role of affect in social relationships but operates as a discursive resource for the reconfiguration of organizational questions as questions about the emotional life of those involved. I will structure this part of the paper anticipating three problems Lacan (1953) identifies, starting with knowledge as grounding for education and interpretation. We will then be in a position to put Lacan to work on this context and on the particular case example.

\section{Knowledge as a circular process}

Neoliberal policies in the public sector are now being implemented by forms of 'New Public Management' (NPM) that are 'characterized by a combination of free market rhetoric and intensive managerial control practices' (Lorenz, 2012: 600). Chris Lorenz (2012) draws attention the way that the reign of NPM entails a transformation of the way that knowledge is assumed to function in universities. Effectiveness - 'the quality of being able to bring about an effect' (ibid.: 604) - is 
replaced by 'efficiency' which pertains to the operation of the system as such. The elision of the difference between the two concepts enables a reduction of 'efficiency' to 'cost-efficiency', which boils down to perpetual reduction in funding in which 'each cut in spending is simply the springboard to the next' (ibid.: 606). Assessment of value then revolves around the course 'module' which is 'defined in terms of a fixed quantity of time investment by both its producers and its consumers' (ibid.: 612), and this requires the standardisation of knowledge formulated in the Bologna Process (Fejes, 2008).

The kind of knowledge of work practices to achieve maximum 'efficiency' in the university thus also requires that the knowledge produced in the university be directly observable and measurable. To grasp this, Lorenz turns to Harry Frankfurt's (2005) analysis of 'bullshit' to notice statements that comprise NPM discourse:

(1) statements that identify the quality of education with quantitative educational output ('qualispeak'); (2) statements that identify the academic worth of research with economic market value ('valorizationspeak'); and (3) statements that identify the underfunded public universities (of the US, the Netherlands, Germany, or France) with top private universities of the US ('topspeak' or 'excellencespeak'). (Lorenz, 2012: 626)

In line with the shift from effectiveness to efficiency, there is a corresponding shift from truth to the circularity of knowledge and the effects statements might have within it. As Lorenz (2012) points out, 'bullshit does not refer to the truth as such', it is 'neither based on a belief that what is being claimed is true nor, as in a lie, that it is untrue' (ibid.: 627). He turns to Frankfurt to spell out the implications of this with respect to appeals to the authority of the truth: 'The bullshitter', Frankfurt (2005: 34) writes 'ignores these demands altogether', and '[b]y virtue of this, bullshit is a greater enemy of the truth than lies are'.

This shift also has implications for the way that knowledge is invested with power, the way it is invested with affect and then, necessarily so given the gendered division of labour in this culture, the way that recruits men and women to it. Valerie Hey (2011), drawing on work by Arlie Hochschild 
(1979), points that one of the academic institution's unspoken 'feeling rules' is that 'the only emotional performance sanctioned is that of aggressive go-getting' (Hey, 2011: 214), and, drawing on Beard et al. (2007), that 'master emotions' of pride and shame feature in education 'with its fixation with marking the absolute boundary between success and failure' (Hey, 2011: 211). Studies of work intensification among UK university lecturers have drawn attention the role of 'emotional labour', defined as 'the effort which is required to display that which are perceived to be the expected emotions' (Ogbonna and Harris, 2004: 1189).

The increase in importance of emotional labour in the private and public sectors means that there is a distribution of power in management in higher education where 'the executive positions are overwhelmingly occupied by men, whilst middle management is more the domain of women', and this 'splits the male decision-makers from the tier of people who implement them' (Hey, 2011, 216). This then raises the spectre of a particular form of bureaucratic control that employs feminist rhetoric (Ashcraft, 2006), and then of reaction to this control by men who attempt to assert their own masculinity which they feel to be under threat.

\section{An ethics of gendered care}

New Public Management in the university sector, and not only there, claims to be 'antibureaucratic', a claim that is 'suspect from the outset' (Lorenz, 2012: 605). But the warrant for that claim lies, in part, in the way that work in the service sector has recruited the stereotypical qualities of women's intuitive and relational activities in the home and harnessed them to an ethos of customer care. In the process this 'feminisation' of work that Hochschild (1983) describes in her accounts of 'emotional labour' also recruits, to borrow a phrase from Judith Butler (1997), the 'passionate attachment' of subjects to their own identity to their relation to work and to the organisation in which they work.

We are clearly drawn into a psychoanalytic frame of reference of some kind when we are trying to grasp this, and this is spelt out by some recent researchers into the gendering of university knowledge production: 
To conceive of people as holding identifications with/in social space offers a productive way to conceive power intersecting the person/al and institutional/al, the conscious and the unconscious, and thus to explain the process through which the desires of individuals could be articulated into affect-laden social orders, including those of Higher Education. (Hey, 2011: 214)

Critiques of Hochschild which claim that customer service interactions are 'double-edged', that they are 'satisfying as well as distressing for the worker' merely serve to underscore the depth of alienation she is describing (Brook, 2009: 8). The feminisation of work induces a commitment to work, and it hooks and mobilises stereotypical feminine qualities to management agendas that claim to care for those they aim all the more efficiently to adapt to the organisation. In this context 'affect' is no longer a mere resource to be tapped and exploited but becomes a topic of the very discursive procedures that it sustains.

A reflexive attention to the role of 'emotions' at work becomes part of the ethics of gendered care that ensures that occupants of positions of executive and middle-management know their place, perform it and feel it. That is, men usually make decisions at executive level, and often it is women who are told to implement those decisions (Hey, 2011). The link between gender and emotion brings us to the performance of expertise tied to power.

\section{Mastery of what you feel}

One of the necessary paradoxes of the simultaneous blurring and reinforcement of hierarchical management practice in higher education today is that while everyone is invited to become a little 'master' - self-sufficient unto themselves and able to compete in the academic market-place - they are also incited to agonise about their rights and responsibilities to the point where they reconfigure themselves as little 'slaves' beholden to the recognition of their managers, colleagues and, through the machinery of teaching quality evaluations their students. (In the UK this is officially instituted 
through the 'National Student Survey', for example, and in the US unofficially through the 'Rate My Professor' website.)

A researcher subject to this regime will often grin and bear it, hoping that it will end some time, but will usually not be willing to risk their own already precarious position and speak openly to refuse it.

Crucial to this process of regulation and self-regulation is a quasi-therapeutic attempt to reflect upon and master what is felt, which has prompted claims that universities have been subject to a regime of 'therapeutic education' (Ecclestone and Hayes, 2008). Reductive though such a reading of the process is, it does draw attention to the management of emotion as part of the apparatus of power, so that command is supplemented or even replaced with entreaty and appeal for understanding of the predicament of the manager by those they are attempting to pull into line.

We can notice a number of different responses to this by lecturers and researchers. One first response is to conform to this inducement to self-mastery, which they often must do in the 'selfcongratulatory' accounts of academic progress required as part of the research audit. Research audits pretend to provide open transparent evaluations of work, but instead obscure the power relations of the system they perpetuate (Strathern, 2000). Such 'narcissistic autobiographies' are the staple of 'internal institutional currency' and in this respect '[n]eoliberalism spawns endless displays of selflove' (Magee, 2012: 172). A second response linked to this strategy, and which may be part of it, is to retreat into a cynical ironic detached non-relation to what is demanded, that which Lorenz (2012: 620), in a cryptic reference to strategies of disengagement by liberals under Nazism, refers to as 'inner immigration'. A third response is to fold under the pressure, and 'the hidden injuries' of the neoliberal university here are all-too-often invisible, for those who are unable to conform often leave higher education altogether (Gill, 2010). A fourth response is to obey what has been termed, in a theological reading, the 'Performative Absolute' demanded by contemporary human resources management, and offer oneself up as 'living sacrifice'; in this perspective, 'this is the age of the employee as oblate' (Roberts, 2012: 18).

In practice these responses coincide, contradict each other and overlap in the same subject as they confront a demand to give recognition to their masters and show through the performance of 
their emotional labour that they crave recognition themselves. It is via that matrix of responses that mockery, sarcasm, pitying contempt and hopes for revenge and redemption are enacted. These affective responses are almost palpable in the case example staging of a fantasy in which an employee seeks to make visible his humiliation with his assertion that 'I want her to head-butt me in the face in public', but rather than simply 'apply' psychoanalysis to this case example and its organisational context we can go further with Lacan to show not only how psychoanalysis is useful to help us understand these events but how psychoanalysis operates as a structuring discourse for their subjects to respond to surveillance and control.

Lacan's (1953: 202) critique of the place of 'dialectical mastery' in training and then in analysis is worth taking into account here, but this mastery is no longer merely the mastery of knowledge of what the other is feeling. It also gives rise to strategies of refusal which are imagined to be resistance to power on the part of those subject to the discourse of neoliberal education. It sets the scene for the logic of ideological fantasy at work that psychoanalysis is already implicated in and which psychoanalysis can therefore help us to map (Glynos, 2008).

\section{Principles from Lacan's text}

Lacan (1953: 202) describes three problems of psychoanalysis which he glosses at one point as "the child's education by its mother, Samaritan-type aid and dialectical mastery', and a preoccupation with these problems recurs through his text. The three problems of psychoanalysis concerning the governance of knowledge, the pretence to be helping those who are subject to it and the mastery that is enjoyed by those who administer it that Lacan noticed sixty years ago are very relevant to the problems we face in higher education today. They are not only relevant to those who wish to use psychoanalysis to make sense of organisations, but they provide warnings as well as lessons for psychoanalytic researchers and cultural critics (Verhaeghe, 2014). A specific domain of theory and practice that was then mainly outside the university sector has become part of the fabric of what Lacan calls the 'wall of language' that structures the management of academic activity. 
Notwithstanding Lacan's $(1953,201)$ question about applying psychoanalytic method in his later preface to 'The function and field of speech and language in psychoanalysis', or precisely as occasion for posing it, he follows his first diagnosis of what he refers to as 'current problems of psychoanalysis', with the claim that 'In order to home in on the causes of this deterioration of analytic discourse, one may legitimately apply psychoanalytic method to the collectivity that sustains it' (ibid.: 203). I will rehearse Lacan's argument concerning these six principles and bring them to bear on the events and context I have described so far.

\section{Application}

The first principle concerns 'application', which will be complicated as Lacan's text proceeds, and we will that each of these principles will need to be sharpened in relation to the others. Already we can note that these three problems are fuelled by a presumption that there is a point external to the subject from which knowledge can be put to work. This is a presumption that since 1953 has been exacerbated inside psychoanalysis by the turn to developmental models that then inform a kind of pedagogy about and for mothers, by an ethical imperative to help and be seen to help others, and by the use of countertransference as a kind of machinery through which the knowledge the analyst thinks they have of the unconscious of the analysand (the patient undergoing psychoanalytic treatment) is clarified so that more accurate interpretations can be delivered. So, the first point concerning 'application' also concerns the position of the researcher, our own position (Neill, 2011).

The question of application of psychoanalysis is already problematic in this case where it functions not only as an analytic frame which pretends to make sense of the ostensibly 'Oedipal' relationships between senior management and their rivals (former supervisors and then underlings), but also as a form of knowledge which operates as a competitor to that of 'psychology' as the preferred discourse of the department and colleagues within it. Here, in the second moment of the staging of a fantasy in the case example of the employee who wants his department head to head-butt him in the face in public psychoanalysis is also problematic as a mode of knowledge for interpreting what is going on for my position is as a researcher already attributed with that knowledge. This is 
what I referred to when I said that I was 'implicated' in it. This form of knowledge is also implicated in the turn to emotional aspects of discipline and surveillance, and the attempt to resist it. Knowledge in education has expanded its field of operation, has turned into a circular and efficient process in which truth is irrelevant or an obstacle to it, and distributes affectively-charged positions of management and implementation to the gendered subjects who occupy it.

Speech, truth

The second principle concerns the relation between speech and truth. Lacan points out that what the problems have in common is the temptation of abandoning 'the foundation of speech' (ibid.), and this is important because when the analyst turns themselves into one who knows, when they really believe that they do know how others develop, feel and speak, the transformative power of speech is replaced with an interpretive grid. This is an irresolvable conundrum for academics who would like to see the world conform to their own favourite theory of it. If, as Lacan (1953: 246) claims, 'speech commits its author by investing its addressee with a new reality', then in psychoanalysis as such, in the clinic, we are not only implicated in what we describe but we make it possible for the analysand to create and commit themselves to a new reality.

In this text the creation and commitment to a new reality is conceptualised by Lacan as 'true speech': 'Analysis can have as its goal only the advent of true speech and the subject's realization of his history in its relation to a future' (ibid.: 249). This second principle is one we will always, in the kind of research we carry out into work organisations, violate to some extent because we are noticing, explicating and writing about what is going on (Cederström and Hoedemaekers, 2010). We are doing these things in a way that does not directly and immediately enable our participants to produce and then enact interpretations themselves as they would in analysis. Instead, we are implicated in this process at a distance, perhaps facilitating at second remove what Lacan (ibid.: 245) is describing here when he writes '... in its symbolizing function, speech tends toward nothing less than a transformation of the subject to whom it is addressed by means of the link it establishes with the speaker - namely, by bringing about a signifying effect.' 
However, this 'transformation of the subject' that occurs in speech does not only configure the speaking subject as a free agent, that kind of subject who is fantasised to emerge at the end point of popularised representations of psychoanalysis, and of psychoanalysis taught in psychology departments (Richards, 1989). We see in this case example that the subject is also configured as one who becomes all the more subject to the fantasy of eventual escape from their predicament as they describe their powerlessness. The hope that there might be such a place where the truth could be spoken and acknowledge as such is all the more potent in conditions in which language is turned into bullshit, into a form of discourse in which there is no relation to truth. In Lacanian terms we might say that it is as if the Other as a site of demands for truth to be spoken is all but abolished. Hence the preoccupation on the part of my colleague with what I really intended by my actions and a confession by him of what he really wanted. A deeper intentionality which psychoanalytic discourse promises to access becomes the court of appeal and the recourse of those who sense that they are not being listened to.

The wall of language

Let us move on from this second principle concerning 'speech', which 'application' sabotages to some extent, to the role of 'language'. The third principle concerns language and what we could call the function and field of psychoanalytic language and then also speech, psychoanalytic discourse which inhabits institutions and our research today. The human being speaks, but this is, Lacan argues, 'because the symbol has made him man' (ibid.: 229), or made her, we should say, along with the binary opposition that governs how each sex is positioned as gender in language today. Lacan's attention to the structure of language not only gives an opening to something approximating discourse analysis in our research outside the clinic, or even 'Lacanian discourse analysis' (Pavón-Cuéllar, 2010) but also cues us into the shape of a problem at the very moment when we think it is the shape of a solution. That is, when Lacan refers to the 'wall of language' (pp. 233: 241) at different points in the text, it is to indicate that this language is now - and remember this 'now' is already sixty years ago riddled with psychoanalysis itself. And instead of being riddled with holes by psychoanalysis, it is 
now stuffed full of psychoanalysis so that the riddles we imagine we are solving are often of our own making (Parker, 1997, 2009).

This gives another sense - Nachträglich, from where we are reading this - to Lacan's argument that 'we must be attentive to the unsaid that dwells in the holes in discourse' (ibid., 253), and to his rebuttal of popular psychoanalytic discourse which searches for the unconscious underneath language or in a 'pre-verbal' domain before it, for, he insists, 'the unsaid is not to be understood like knocking coming from the other side of the wall' (ibid.). He is quite explicit about this problem: '... with the mythical manipulations of our doctrine, we bring [the subject] yet another opportunity to become alienated, in the decomposed trinity of the ego*, the superego* and the id*, for example.' Lacan is using here terms marked with an asterisk ('ego', 'superego', 'id') that were introduced and popularised by the English translation of Freud (Timms and Segal, 1988), and he continues 'Here it is the wall of language that blocks speech, and the precautions against verbalism that are a theme of the discourse of "normal" men in our culture merely serve to increase its thickness' (ibid.: 233).

It is in this respect that the staging of the fantasy should be read not so much as the expression of desire that was interior to the mind of the colleague speaking to me about his relation with his head of department but as constituted by the conversation we had together and constructed out of available discursive resources. In this case, and precisely because it is such an affectively-charged fantasy of humiliation and revenge, these discursive resources are fed by psychoanalytic motifs. That is, the psychoanalysis should not be treated as the key to unlock this particular individual subject but as series of narratives concerning desire and possibility, dependence and self-assertion, and suffocating mothering in relation to frustrated masculinity. This, we could say if we were to adopt a psychoanalytic standpoint, is why there is a puzzle that seems to be resolved in the staging of the fantasy, a puzzle that revolves around the power of a head of department as a woman manager doing the bidding of a man who is dean who has already indicated that he can enact revenge on those who exerted power over him. However, what is also important here is that although psychoanalysis does help us trace the shape of this language, it is also, as Lacan points out, part of the 'wall of language' that invites us to believe that there is something more interesting and important behind that wall. 
This brings us to the fourth principle which pertains to how the gap between speech and language is produced and reproduced as a form of alienation and expressed as symptom. There are three aspects of this mutually constitutive relation between alienation and symptom that are important for us as we try to grasp this fourth principle. The first is the way that discourse that presents itself as 'full' at one moment is emptied at the next, the way forms of discourse that pretend to give meaning then deaden it. Lacan (1953: 246) refers to the 'antinomy immanent in the relations between speech and language' such that " $[t]$ he more functional language becomes, the less suited it is to speech, and when it becomes overly characteristic of me alone, it loses its function as language' (ibid.).

The second aspect of this gap is the yearning for relation with another that Lacan is happy enough in this text to gloss as 'intersubjectivity' (p. 247), which is driven by recognition that will flow through speech as the analysand speaks to the analyst and be blocked by the very language that makes that speech possible inside and outside the clinic. Here Lacan (1953: 222) comes close to a romantic humanist conception of the subject that already, of course, contains within it a tragic Freudian sting in the argument when he writes that '... man's desire finds its meaning in the other's desire, not so much because the other holds the keys to the desired object, as because his first object(ive) is to be recognised by the other' (ibid.).

The third aspect of the gap between speech and language is to be seen in its manifestation as symptom. My colleague stages a fantasy for me in our conversation it hardly need be pointed out, in language, and psychoanalysis was from the beginning conceived of as a 'talking cure' in which the unhappiness of the patient is put into words rather than an attempt to divine feelings below the surface of language. As Lacan points out in his 1953 paper, the 'problems of psychoanalysis' each rest on the mistaken, and strictly-speaking non-psychoanalytic supposition, that there should be a mode of sympathetic engagement with the patient that goes beyond their speech, and he argues that this simply leads to the analyst being the master of psychoanalytic discourse who then charitably helps those whose pain is to be interpreted. Instead, and in line with Lacan's argument here, we should view the speech of my colleague enacting a fantasy for me as symptomatic. Lacan (ibid.: 223) puts it like this: 
'... symptoms can be entirely resolved in an analysis of language, because a symptom is itself structured like a language: a symptom is language from which speech must be delivered'. The twist is that in this case the speech reproduces the language it aims to escape from. It enacts as symptom of the organisational context the very problem that it seeks to solve, and the fantasy is produced as if it would give satisfaction that would compensate for the humiliation it hopes to expose. Lacanians would, of course, be attentive to satisfaction as indicating that there is something symptomatic at play in such a description rather than a happy healthy normal state of affairs.

\section{Resistance: the joke}

There is another aspect to the gap constitutive of alienation and the symptom which is already at work in the symptom itself, which is; where there is the power of language there is something that speaks, a fifth principle concerning what we could call 'resistance'. This fifth principle also enables us to grasp the role of jokes in organisations.

With respect to alienation, the alternation between 'action and knowledge' is such that 'The symbolic function presents itself as a twofold movement in the subject' (p. 236), and Lacan indicates how this twofold movement is historically located so that what is conceptualised as 'alienation' of the subject in psychoanalysis is named and reconfigured as 'alienation' of the worker: 'in phase one, a man who works at the level of production in our society considers himself to belong to the ranks of the proletariat; in phase two, in the name of belonging to it, he joins a general strike' (ibid.).

With respect to the symptom, the obsessional character of alienation under capitalism leads to the fantasy that with the master's death the subject will begin to live, 'but in the meantime he identifies with the master as dead and is thus already dead himself' (ibid.: 259).

Now, to name this fifth principle 'resistance' is fraught with difficulties, but the term should be read here as short-hand for 'that which speaks' of the conditions which constitute the subject, and which then and today has to navigate the tender trap of psychoanalytic discourse which sets up an opposition between what Lacan calls the "recourse to "affectivity" (p. 207) on the one hand and use of "the verb "to intellectualize" (ibid.) on the other. What concerns him here is the "dialectical 
incapacity' (ibid.) of the forms of psychoanalysis he rejects to comprehend this opposition; it is not, and this is crucial, that he is avoiding 'affect' or endorsing the 'intellectualising' manoeuvres of those who do avoid it.

One way of approaching that opposition between affect and intellectualisation in discourse is by taking jokes seriously. In a joke we hear a strategy of engagement with power that closes over what it pretends to expose: 'It is truth, in fact, that throws off the mask in coming out of his mouth, but only so that the joke might take on another and more deceptive mask' (ibid.: 224); this gives rise to an illusion of resistance which serves to perpetuate what it aims to subvert, 'sophistry that is merely a stratagem', 'logic that is merely a lure', 'comedy that tends merely to dazzle' (ibid.).

We have seen how jokes operate as a guise of power, and how jokes pretend to unravel that power in impotent and secretive strategies of what is fantasised to be 'resistance' to it. The fantasy here is that the master will expose themselves, but in the meantime it is necessary to be all the more obedient so that that future exposure will be possible and satisfying. The recourse to deeper hidden wishes, the fantasy of the head of department head-butting the victim in the face in public for example, provides sustenance, but cruel comfort which is fed by a psychoanalytic discourse of public personae and concealed feelings. 'Hence', Lacan (1953: 259) notes, the slave 'can accept to work for the master and give up jouissance in the meantime; and unsure as to when the master will die, he waits.' And meantime he suffers symptomatically and expresses that suffering in jokes that pretend to resist it.

\section{The clinic}

The extraction of general principles from Lacan's text, even with the qualifications as to historical specificity that his reference to the 'proletariat' reminds us of, needs to bear in mind how each principle functions in relation to the others. And this is where the question of 'application' as the first principle brings us to a sixth principle which concerns the specificity of the field of application of psychoanalytic method. That is, Lacan (1953:214) alerts us in this text to the clinic as a limited domain, as a site in which psychoanalysis works, when he writes ' $\ldots$ if the originality of the method 
derives from the means it foregoes, it is because the means that it reserves for itself suffice to constitute a domain whose limits define the relativity of its operations.'

This could be read as a warning that psychoanalysis only 'applies' in the clinic, and that any attempt to expand its field of operation would serve to 'misapply' it. It would then be inappropriate to use psychoanalytic concepts to interpret and unravel the hidden meanings in the discourses and practice in non-psychoanalytic contexts, in non-psychoanalytic organisations. But, as Lacan points out, psychoanalysis is present as a symbolic resource that structures, albeit in distorted form, the psychoanalytic institution, 'its own corporation' (ibid.: 200). That is precisely part of the problemthat it structures the institution in distorted form - and it is this very structuring that makes a work organisation amenable to a psychoanalytic reading.

So, the other way of reading Lacan's comments about the way that psychoanalytic method suffices 'to constitute a domain whose limits define the relativity of its operations' is to take seriously the way that psychoanalytic language today inhabits and structures institutions such that psychoanalytic speech becomes a liability and an opportunity. It is both an opportunity and a liability in our attempts to deal with this function of psychoanalysis today as part of the 'wall of language'.

This is especially so, we might suspect, in the field of education which has endeavoured to use psychoanalysis to understand the impossibility of its own mission and encouraged a reflexive stance which borrows on Freudian precepts (Britzman, 2011). Lacan has some caustic comments about education in this text, which include his complaints about 'a conception of analytic training that is like that of a driving school' (ibid.: 200), which embed his critique in comments about obsessional 'clock time' in the universe we inhabit today (ibid.: 257), and about 'the brazen face of capitalist exploitation' (ibid.: 236) which invites certain strategies of identification and resistance. Lacan points to this context in which psychoanalysis operates not only to counterpose the true speech of the analysand to the falsity of reigning systems of knowledge. He is just as concerned with the way psychoanalysis may come to function as part of the 'wall of language' it pretends to dismantle. That second aspect of his 1953 paper on 'The Function and Field of Speech and Language' needs to be heeded today by those of us seeking to use psychoanalysis to analyse discipline and subjectivity in neoliberal education in our universities. 


\section{Conclusions}

There are many different competing contradictory and overlapping forms of psychoanalytic discourse at work in the field of culture and in organisations today (Kenny and Fotaki, 2014). These forms of psychoanalytic discourse constitute frames for the 'emotionalising' of labour and experience which may be grasped in their function within discourse and practice as reinforcing class boundaries or as 'racialising' work by different psychoanalytic traditions, not only Lacanian (e.g., Gunaratnam and Lewis, 2001). This is not to be relativist, but to attend to the way specific domains are constituted whose limits define the relativity of its operations.

I have extracted some principles from one of Lacan's early texts to read this situation. Lacan's work is notoriously resistant to one accessible transparent synthesis of the arguments, and the many other written and spoken texts he produced offer a variety of vantage points on questions of enjoyment, discourse, education, mastery and the production of what is usually referred to in popular and academic culture as 'gender' (Clemens and Grigg, 2006). These issues would undoubtedly look very different from psychoanalysis of the 'later' Lacan (Voruz and Wolf, 2007).

The 'logic of fantasy' that I have described in this particular case example is spoken and woven out of available forms of language, but it is not merely a discursive construction which may then be dismantled so that those subject to it may speak the truth, for it already speaks of 'enjoyment' within political economy (Glynos, 2012). The position of the subject is suffused with and organised by forms of emotion that circulate between them and others, and this produces affective economies which can be traced in critical analysis (Ahmed, 2004). Lacan, and Lacanian discourse analysis thus includes in its scope attention to affect and to that which escapes and disrupts discourse (Parker and Pavón-Cuéllar, 2013).

Our attempt to grasp the reality of psychoanalytic reasoning outside the clinic must be grounded in the specificity of the clinic as site of psychoanalytic practice (Parker, 2011), but also take account of the way that this reasoning structures subjectivity in contemporary culture (Parker, 2009). Organisations that inculcate a discourse about 'emotion' and attempt to make managers and 
employees speak about how they feel about their colleagues and their work are sites in which aspects of psychoanalytic theory can be made to function as the shape of that which locks people in place, which we as researchers might then stumble upon as if only we had the keys that fit this lock. This means that our reading of these discourses that flow through culture and organizations are not from a neutral ground external to them. Lacanian theoretical discourse, while apparently so alien to the contexts in which we put it to work, is uncannily implicated in it, and that is precisely what can give it such a sharp deconstructive edge. A Lacanian discourse analysis, for example, would not regard the narratives it studies as analysable discourses to be analysed by us, but as analysing discourses. That is to say that we do not adopt a position outside the material in order to 'apply' the analysis to it, but we attend to the way the narrative reflects and makes sense of itself (Pavón-Cuéllar and Parker, 2013). The proliferation of psychoanalytic forms of discourse, modes of reasoning, narratives of experience and embodied affective responses to work today means that we are faced with exactly the questions that Lacan was concerned with sixty years ago, but more so. Psychoanalysis has come to structure what has been termed an 'age of interpretation' in which the correct Lacanian response would, perhaps, be to 'cut' the discourse rather than feed it (Miller, 1999).

This paper has explored the staging of fantasy in a specific organisation, with an allocation of roles to higher and middle-level management that is, to some extent, stereotypical, but which also reflects current literature on the mobilization of affect at work. I took the analysis on affect at work further by showing not only that there is a mobilization of affect in relations of power, but also that psychoanalytic discourse plays a particular role in that. This is not to imply that before contemporary neoliberal management practices, or before the popularization of psychoanalysis, universities were free and open spaces, free of problems. Instead, this is a specific analysis of a specific constellation of issues that characterise education today. Neoliberal education is a field of speech and language which is amenable to a Lacanian reading, but that is where our problems begin and against which we attempt to speak the truth. 


\section{References}

Ahmed, Sara (2004) The Cultural Politics of Emotion. Edinburgh: Edinburgh University Press.

Ashcraft, Karen (2006) 'Feminist-bureaucratic control and other adversarial allies: Extending organised dissonance to the practice of "new" forms', Communication Monographs 73(1): $55-86$.

Beard, Colin, Clegg, Sue and Smith, Karen (2007) 'Acknowledging the affective in higher education', British Educational Research Journal 33(2): 235-252.

Britzman, Deborah (2011) Freud and Education. London: Routledge.

Brook, Paul (2009) 'The Alienated Heart: Hochschild's "emotional labour" thesis and the anticapitalist politics of alienation', Capital \& Class 33(7): 7-31.

Burman, Erica (2009) 'Beyond "emotional literacy” in feminist and educational research', British Educational Research Journal 35(1): 137-155.

Cederström Carl and Hoedemaekers, Casper (eds) (2010) Lacan and Organization. London: MayFly Books.

Clemens, Justin and Grigg, Russell (eds) (2006) Jacques Lacan and the Other Side of Psychoanalysis. Durham, NC: Duke University Press.

Contu, Alessia, Driver, Michaela. and Jones, Campbell. (2010) 'Jacques Lacan with Organization Studies', Organization 17(3): 307-15.

De Vos, Jan (2012) Psychologisation in Times of Globalisation. London: Routledge.

Duncan, W. Jack (1982) 'Humor in Management: Prospects for Administrative Practice and Research', The Academy of Management Review, 7(1): 136-142.

Ecclestone, Kathryn and Hayes, Dennis (2008) The Dangerous Rise of Therapeutic Education. London and New York: Routledge.

Ellis, Carolyn and Bochner, Arthur (2000) 'Autoethnography, personal narrative, reflexivity’, in N. K. Denzin and Y. S. Lincoln (eds) Handbook of qualitative research (2nd edn.), pp.733-768. Thousand Oaks, CA: Sage. 
Fejes, Andreas (2008) 'Standardising Europe: The Bologna Process and new modes of governing', Learning and Teaching: The International Journal of Higher Education in the Social Sciences 1(2): 25-49.

Frankfurt, Harry (2005) On Bullshit. New York: Princeton University Press.

Gill, Ros (2010) 'Breaking the Silence: The Hidden Injuries of the Neoliberal University', in R. Flood and R. Gill R (eds) Secrecy and Silence in the Research Process: Feminist Reflections, pp. 228-244. London: Routledge.

Glynos, Jason (2012) 'The Place of Fantasy in a Critical Political Economy: The Case of Market Boundaries,' Cardozo Law Review 33(6): 101-139.

Glynos, Jason (2008) 'Ideological fantasy at work’, Journal of Political Ideologies 13(3): 275-296.

Gunaratnam, Yasmin and Lewis, Gail (2001) 'Racialising emotional labour and emotionalising racialised labour: Anger, fear and shame in social welfare', Journal of Social Work Practice 15(2): 131-148.

Harvey, David (2007) A Brief History of Neoliberalism. Oxford: Oxford University Press.

Hey, Valerie (2011) 'Affective asymmetries: academics, austerity and the mis/recognition of emotion', Contemporary Social Science 6(2): 207-222.

Hochschild, Arlie (1979) 'Emotion work, feeling rules and social structure', American Journal of Sociology 85(3): 551-575.

Hochschild, Arlie (1983) The Managed Heart: Commercialisation of Human Feeling. Berkeley, CA: University of California Press.

Hodgson, Damian (2005) “"Putting on a Professional Performance”: Performativity, Subversion and Project Management'. Organization, 12(1): 51-68.

Kenny, Kate and Fotaki, Marianna (eds) (2014) The Psychosocial and Organisation Studies: Affect at Work. London: Palgrave.

Klein, Naomi (2008) The Shock Doctrine: The Rise of Disaster Capitalism. Harmondsworth: Penguin. Lacan, Jacques (1953) 'The function and field of speech and language in psychoanalysis', in J. Lacan (2006) Écrits: The First Complete Edition in English (translated with notes by B. Fink in collaboration with H. Fink and R. Grigg) (pp. 237-268). New York: Norton. 
Lacan, Jacques (2006) Écrits: The First Complete Edition in English (translated with notes by B. Fink in collaboration with H. Fink and R. Grigg). New York: Norton.

Lacan, Jacques (2007) The Other Side of Psychoanalysis: The Seminar of Jacques Lacan, Book XVII (translated by R. Grigg). New York: Norton.

Lorenz, Chris (2012) 'If You're So Smart, Why Are You under Surveillance? Universities, Neoliberalism, and New Public Management', Critical Inquiry 38(3): 599-629.

Magee, Paul (2012) 'The scholarly affair is self-love', TOPIA: Canadian Journal of Cultural Studies 28: $171-179$.

McGettigan, Andrew (2013) The Great University Gamble: Money, Markets and the Future of Higher Education. London: Pluto Books.

Miller, Jacques-Alain (1999) 'Interpretation in Reverse', Psychoanalytical Notebooks of the London Circle 2: 9-18.

Neill, Calum (2011) Lacanian Ethics and the Assumption of Subjectivity. London: Palgrave.

Ogbonna, Emmanuel and Harris, Lloyd (2004) 'Work intensification and emotional labour among UK university lecturers: An exploratory study', Organization Studies 25(7): 1185-1203.

Parker, Ian (2009) Psychoanalytic Mythologies. London: Anthem.

Parker, Ian (2011) Lacanian Psychoanalysis: Revolutions in Subjectivity. London: Routledge.

Parker, Ian and Pavón-Cuéllar, David (eds) (2013) Lacan, Discourse, Event: New Psychoanalytic Approaches to Textual Indeterminacy. London: Routledge.

Pavón-Cuéllar, David (2010) From the Conscious Interior to an Exterior Unconscious: Lacan, Discourse Analysis and Social Psychology. London: Karnac.

Pavón-Cuéllar, David and Parker, Ian (2013) 'From the white interior to an exterior blackness: A Lacanian discourse analysis of apartheid narratives', in G. Stevens, N. Duncan and D. Hook D (eds) Race, Memory and the Apartheid Archive: Towards a Transformative Psychosocial Praxis. London: Palgrave.

Richards, Barry (1989) Images of Freud: Cultural Responses to Psychoanalysis. London: Weidenfeld Dent. 
Roberts, Ron (2012) 'Contemplation and the "Performative Absolute": Submission and identity in managerial modernity', Journal of Management, Spirituality and Religion 9(1): 9-29.

Stavrakakis, Yannis (2008) 'Peripheral vision: Subjectivity and the organized Other: Between symbolic authority and fantasmatic enjoyment', Organization Studies, 29(7): 1037-1059.

Strathern, Marilyn (2000) 'The tyranny of transparency', British Educational Research Journal 26, pp. 309-321.

Timms, Edward and Segal, Naomi (eds) (1988) Freud in Exile: Psychoanalysis and its Vicissitudes. New Haven and London: Yale University Press.

Verhaeghe, Paul (2014) What About Me?: The Struggle for Identity in a Market-Based Society. Brunswick, Australia and London: Scribe.

Voruz, Veronique and Wolf, Bogdan (eds) (2007) The Later Lacan: An Introduction. New York: State University of New York Press.

Went, Robert (2000) Globalization: Neoliberal Challenge, Radical Responses. London: Pluto.

Zajda, Joseph (ed.) (2005) International Handbook on Globalisation, Education and Policy Research: Global Pedagogies and Policies. Dordrecht, Netherlands: Springer. 